\title{
A UTILIZAÇÃO DE ADESIVOS AUTOCONDICIONANTES EM ORTODONTIA: O ESTADO DA ARTE
}

\section{THE USE OF SELF-ETCHING ADHESIVES IN ORTHODONTICS: THE STATE OF ART}

\author{
Fabiane Renó de Souza*; Suellen Bispo Rodrigues**; \\ Emigdio Enrique Orellana Jimenez ${ }^{* * *}$; Ulisses Coelho**** \\ * Acadêmica do curso de Odontologia da Universidade Estadual de Ponta Grossa - \\ UEPG. E-mail: fabinha_pg@hotmail.com \\ ** Acadêmica do curso de Odontologia da Universidade Estadual de Ponta Grossa - \\ UEPG. E-mail: suh_rdgs02@hotmail.com \\ *** Professor Titular da Disciplina de Ortodontia do curso de Odontologia da \\ Universidade Estadual de Ponta Grossa - UEPG. \\ **** Professor Doutor Associado da Disciplina de Ortodontia do curso de \\ Odontologia da Universidade Estadual de Ponta Grossa - UEPG.
}

Recebido para publicação em 01/09/2010

Aceito para publicação em 20/10/2010

\section{RESUMO}

O objetivo deste estudo foi revisar a respeito dos adesivos autocondicionantes quanto às características físico-químicas, as modificações suscitadas no esmalte, $\mathrm{o}$ tempo médio de aplicação e sua efetividade clínica em Ortodontia. Concluiu-se que os adesivos autocondicionantes: apresentam em sua composição a incorporação de derivados do ácido carboxílico (4-MET) ou monômeros fosfonados (Fenil-P, 10MDP e PENTA), a presença de água $\left(\mathrm{H}_{2} \mathrm{O}\right)$ e $\mathrm{pH}$ em torno de 1 a 2; proporcionam uma perda menor de quantidade de esmalte e menor risco de fratura de esmalte em relação aos adesivos convencionais; o tempo de aplicação deve seguir as normas dos fabricantes e a resistência de união apresenta variabilidade de resultados, principalmente em Ortodontia. Sugere-se que mais estudos devam ser realizados para analisar a eficiência clínica destes adesivos.

Palavras-Chave: Autocondicionantes. Colagem. Condicionamento. Braquetes. Ortodontia.

\begin{abstract}
The aim of this study was to review the literature about self-etching adhesives concerning their physical-chemical characteristics, the changes on the enamel surface, the etching time and their clinical effectiveness in Orthodontics. It was concluded that self-etching adhesives present in their composition the incorporation of carboxylic acid derivatives (4-MET) or phosphoric monomers (Fenil-P, 10-MDP and PENTA) the presence of water $\left(\mathrm{H}_{2} \mathrm{O}\right)$ and $\mathrm{pH}$ around 1-2; they also provide a smaller amount of enamel loss and smaller risks of fracture than conventional
\end{abstract}


adhesives; the application time should follow manufacturer's recommendation and the shear bond strength presents variability of results, mainly in Orthodontics. Further studies are needed to analyze the clinical efficiency of these adhesives.

Keywords: Self-etching. Bonding. Etching. Brackets. Orthodontics.

\section{Introdução}

No início da prática ortodôntica, utilizava-se a técnica de multibandagem dos dentes, o que prejudicava a estética e muitas vezes, induzia agressões aos tecidos gengivais. Para suprir essas desvantagens desenvolveu-se a técnica de colagem direta de braquetes, a qual favoreceu a higienização, a diminuição do custo e do tempo da execução do tratamento (FLORIANO, 2001; TORTOMANO, 2002).

A tendência atual da Ortodontia é a simplificação dos procedimentos clínicos, para um melhor atendimento ao paciente e diminuição do tempo de consulta. Para esse fim, novos materiais foram desenvolvidos, tais como: resinas fluoretadas, agentes hidrófilos, adesivos com associação de ácidos e primers, braquetes com adesivo incorporado à base (TATIM, 2010).

Os sistemas adesivos odontológicos têm recebido modificações e contribuições de conteúdo e técnica desde 1956, quando Buonocore (1955) idealizou o primeiro agente de união. Atualmente, os fabricantes desenvolveram os adesivos autocondicionantes, sistemas representativos de uma tentativa de simplificação da técnica, por meio da eliminação de passos clínicos, na qual não é necessária a realização do condicionamento ácido, responsável pela desmineralização de esmalte ou dentina em um passo operatório isolado (MIYAZAKI, 1999).

O estágio evolutivo dos sistemas adesivos autocondicionantes ocorreu principalmente na década de 1990; recentemente introduzidos no mercado, são conhecidos, também, por adesivos de $6^{a}$ geração. Os adesivos autocondicionantes são fundamentados em substâncias capazes de atuar ao mesmo tempo como condicionadores de esmalte dental e dentina e como primers, por impedirem que ocorra uma camada desmineralizada e não infiltrada por adesivo, e assim, permitir que a desmineralização e penetração do adesivo ocorram simultaneamente. Pela ausência da etapa de lavagem, a hidroxiapatita dissolvida pelo adesivo autocondicionante não é removida e continua incorporada (GARONE FILHO, 2002).

A principal característica química que difere os sistemas convencionais dos adesivos autocondicionantes é a incorporação de monômeros acídicos (derivados do ácido carboxílico ou fosfonados) em sua composição. Exemplos desses monômeros são: 4-MET, Fenil-P, 10- MDP e PENTA. Contudo, de forma semelhante aos sistemas adesivos convencionais que necessitam de um condicionamento ácido prévio com ácido fosfórico, os sistemas adesivos autocondicionantes também possuem água em sua composição a fim de neutralizar a ação ácida e não causar uma excessiva desmineralização na superfície tratada (REIS, 2009).

Considerando ser um material recentemente introduzido na prática odontológica, os adesivos autocondicionantes ainda trazem dúvidas quanto ao seu uso, à sua eficiência, à relação custo/benefício, às vantagens e desvantagens, em relação aos sistemas adesivos convencionais.

O objetivo deste estudo é realizar uma revisão de literatura a respeito dos adesivos autocondicionantes, para descrever:

1. Suas características físico-químicas;

2. As modificações suscitadas no esmalte;

3. O tempo médio de aplicação;

4. Sua efetividade clínica em Ortodontia.

\section{Revisão de Literatura}

1. Propriedades físico-químicas dos adesivos autocondicionantes e modificações suscitadas no esmalte.

Os sistemas adesivos autocondicionantes apresentam-se de duas formas: autocondicionantes 
de 2 passos, também denominados de primers autocondicionantes, onde há a associação entre primer e ácido, que é aplicado primeiramente, seguido da aplicação do adesivo; e os sistemas autocondicionantes de 1 passo (all-in-one), nos quais foram unidos o primer ácido e a resina adesiva em uma única solução que é aplicada diretamente sobre os substratos dentários. Alguns sistemas desta última categoria apresentam o primer/ácido/adesivo em compartimentos separados na embalagem a fim de evitar a alteração dos elementos fotossensíveis pela substância ácida ${ }^{8}$. Como exemplo deste sistema, na Ortodontia, temos o Transbond Self-etching Plus que apresenta um expressivo uso (TATIM, 2010; REIS, 2008; PERDIGÃO, 2006).

Em 1999 foi introduzido no mercado odontológico o conceito do sistema adesivo all-in-one, com o produto Prompt L-Pop (3M ESPE). Essa denominação se refere à incorporação de monômeros mais ácidos, solventes, diluentes e água em uma única solução (ou em duas soluções, mas somente um passo clínico) que desempenha as funções de desmineralização, primer e adesivo. De acordo com Frey (2000), a solução ácida é aplicada em somente um passo clínico sobre a superfície do esmalte para promover a dissolução da hidroxiapatita e criar o padrão de condicionamento. Após leve secagem e fotoativação, forma-se uma fina camada do adesivo na superfície do esmalte, suficiente para promover a retenção micromecânica do material restaurador.

Com base no que relata Miyazaki (2000), na técnica do autocondicionamento, os adesivos denominados self-etch diferem de seus antecessores pela ausência da etapa isolada de aplicação do ácido, visto que o passo do condicionamento ácido foi agregado à aplicação dos monômeros adesivos. Os adesivos de 2 passos clínicos são compostos basicamente por monômeros ácidos e derivados, monômeros hidrófilos e água, contidos em um frasco (primer ácido), enquanto um segundo frasco (bond ou adesivo) apresenta concentrações balanceadas de monômeros hidrófilos e hidrófobos. Nesse processo não é necessário lavar a superfície do substrato após a aplicação do primer ácido, e os produtos da desmineralização ou resíduos do ácido são incorporados e polimerizados juntamente com o adesivo (PERDIGÃO, 2003). Os monômeros ácidos presentes nos sistemas autocondicionantes podem ser monômeros derivados do ácido carboxílico (4-MET) ou monômeros fosfonados (Fenil-P; 10-MDP; PENTA).

Netto et al. ${ }^{12}$ mostram exemplos de monômeros ácidos utilizados em adesivos autocondicionantes, que apresentam em sua formulação química produtos como o monômero Fenil Fosfato (Fenil-P) Metacriloxietilfenilfosfato (Clearfil Liner Bond 2 e Clearfil Liner Bond 2V - Kuraray), monômeros Fosfato MDP - Metacriloxidecildihidrogenofosfato (Clearfil SE Bond - Kuraray) e o éster fosfórico Metacrilato (Prompt L-Pop - ESPE).

Similarmente aos sistemas adesivos convencionais que necessitam de um condicionamento ácido prévio com ácido fosfórico, os sistemas adesivos autocondicionantes também possuem água em sua composição. A função da água é ionizar os monômeros acídicos que, por sua vez, se tornam aptos a desmineralizar a smear layer e a dentina subjacente para formar uma camada híbrida verdadeira (REIS, 2009).

Para Reis et al.(2009) e Perdigão et al.(2003) os adesivos autocondicionantes na Ortodontia, correspondem a associação de ácido fosfórico com ésteres metacrilatos, com $\mathrm{pH}$ de aproximadamente 1. O grupo fosfato do ácido fosfórico- éster metacrilato dissolve e remove o cálcio da hidroxiapatita. Após um leve jato de ar e fotopolimerização, o ácido fosfórico incorpora-se ao cálcio formando um complexo hibridizado. Segundo Romano et al. (2007) o sistema Transbond Plus Self-Etching Primer (3M Unitek, Monrovia, CA) foi desenvolvido especialmente para colagem ortodôntica com fórmula química similar ao ácido fosfórico, porém com duas cadeias de primer que formam uma matriz sólida. De acordo Cacciafesta et al. (2003) o Transbond Plus proporciona valores de resistência adesiva ao cisalhamento (RAC) similares aos adesivos convencionais. Paschos et al. (2007) concluíram que o ácido fosfórico produz mais fraturas de esmalte do que o primer autocondicionante, devido possivelmente a reduzida profundidade de desmineralização do uso de autocondicionante. 
Segundo De Munck (2005) e Van Landuyt (2007), dependendo da agressividade do condicionamento, eles podem ser subdivididos em fortes, moderados e suaves. Os produtos considerados fortes usualmente têm $\mathrm{pH} 1$ ou abaixo de 1, como o Adper Prompt L-Pop (3M ESPE), o Xeno III (Dentsply) e o Tyrian SPE (Bisco). A alta acidez resulta em uma desmineralização mais profunda. Para aqueles classificados como moderados, o pH está em torno de 1,5. Exemplos são o Optibond Solo Plus SE (Kerr), o AdheSE (Ivoclar Vivadent) e o One-Up Bond F Plus (Tokuyama Dental). A desmineralização não é tão profunda. Geralmente os adesivos autocondicionantes chamados de suaves têm $\mathrm{pH}$ em torno de 2. Exemplos desses produtos são o UniFil Bond (GC), o Clearfil SE Bond e o Clearfil S3 Bond ou tri-S Bond (Kuraray) e o Hybrid Bond (Sun Medical). Ocorre uma desmineralização parcial e menos agressiva do substrato dental, conservando hidroxiapatita residual. De qualquer modo, suficiente porosidade na superfície é criada para obter uma união micromecânica para a hibridização.

Os monômeros ácidos geralmente têm $\mathrm{pH}$ igual a 2 e o ácido fosfórico tem o $\mathrm{pH}$ igual a 0,6 ; por esse motivo, acredita-se que os adesivos autocondicionantes não são capazes de condicionar corretamente o esmalte não biselado e a dentina esclerosada. É recomendado o condicionamento do esmalte com ácido fosfórico antes de se usar o sistema autocondicionante para garantir um condicionamento eficiente sobre a estrutura (LOPES, 2004).

Devido ao fato de serem ácidos e não serem lavados após sua aplicação poderia - se pensar que os autocondicionantes causam uma desmineralização ilimitada dos tecidos dentários. No entanto, de acordo com Carvalho et al.(2004), isso não ocorre, pois os tecidos mineralizados do dente possuem capacidade de tamponamento das substâncias ácidas do material, neutralizando, após alguns segundos, sua ação desmineralizante.

Em estudo realizado por Hosein et al.(2004) foi avaliada a perda de esmalte com adesivos autocondicionantes pelo processo de colagem, descolagem e limpeza do esmalte após a utilização de um adesivo autocondicionante e compararam com valores obtidos com condicionamento convencional. A partir disso, concluíram que mais esmalte é perdido por meio da técnica convencional do que o uso de autocondicionante, quando da remoção do adesivo remanescente por meio de fresas. Na descolagem, pela técnica convencional o adesivo remanescente foi maior sobre a superfície de esmalte do que o autocondicionante.

A interface entre esmalte e adesivo pôde ser observada com auxílio de um microscópio eletrônico de varredura, por meio de um estudo realizado por Yanamoto et al. em 2007. O esmalte foi condicionado com ácido fosfórico $37 \%$ e comparado com um adesivo autocondicionante. A microscopia de varredura mostrou que o condicionamento com ácido fosfórico $37 \%$ parecia produzir mais perda de esmalte do que o condicionamento com o adesivo autocondicionante. Além disso, a interface esmalte/ adesivo demonstrou uma estrutura mais irregular quando o condicionamento foi com ácido fosfórico $37 \%$.

\section{Tempo de aplicação e efetividade clínica dos adesivos autocondicionantes}

A colagem direta de braquetes ortodônticos ao esmalte dental tem sido extensivamente estudada devido à importância biomecânica de uma interface estável entre o material usado para colagem e o braquete, bem como o material e o esmalte, para que cargas geradas pela colocação de um arco ativado possam ser transferidas aos dentes (ELIADES, 2000). No que diz respeito à resistência de união dos braquetes ortodônticos, Ryou et al. (2008) afirmaram que a colagem dos braquetes ortodônticos deve fornecer resistência suficiente para suportar as forças mastigatórias bem como o estresse gerado pelos arcos ortodônticos.

Dentre os testes para a avaliação da resistência de união, os testes de cisalhamento são utilizados para o estudo das interfaces braquete-adesivoesmalte, por representar aproximadamente o que ocorre na prática clínica (MILLET, 1996; VALLETA, 2007). De acordo com esses autores, a resistência adesiva deve ainda permitir a descolagem sem alterar a superfície do esmalte. 
Reynolds, em 1975, sugeriu que os valores de resistência adesiva ao cisalhamento (RAC) entre 6 e $8 \mathrm{MPa}$ são adequados para as situações clínicas. Para Retief (1974), valores menores de 13,8 MPa são seguros por não causarem fraturas de esmalte.

Segundo estudo realizado por Oliveira et al. (2001) em dois sistemas adesivos autocondicionantes (Prompt - ESPE, Clearfil SE Bond - Kuraray) comparados a um convencional (Scotchbond Multipurpose $-3 \mathrm{M}$ ) visando avaliar a resistência de união ao cisalhamento. Os valores encontrados para a resistência de união dos autocondicionantes variaram de 2,55 $\mathrm{MPa}$ a 12,42 $\mathrm{MPa}$, enquanto que o adesivo convencional obteve valores de $8,18 \mathrm{MPa}$ a 9,15 MPa. Com base nos resultados, concluíram que os novos sistemas adesivos apresentaram efetiva adesão, igual ou até melhor que os sistemas convencionais.

Entretanto, de acordo com outros estudos realizados por Grubisa et al. (2004) e Retamoso et al.(2006), a resistência de união foi significativamente maior com a utilização de ácido fosfórico $35 \%$ do que com o sistema autocondicionante. $\mathrm{O}$ uso do ácido fosfórico teve uma taxa de fratura menor de esmalte do que no autocondicionante. $\mathrm{O}$ autocondicionante reduz alguns passos necessários para a colocação de braquetes, mas não afeta negativamente a força de adesão, indicando que a técnica não é tão sensível como à técnica do uso de ácido fosfórico mais adesivo convencional. Esse fato implica em uma possível indicação destes sistemas adesivos na colagem direta de braquetes ortodônticos. Scougall-Vilchis et al. (2009) sugeriram que os adesivos autocondicionantes Transbond Plus (3M Unitek), Clearfil Mega Bond (Kuraray), primers A e B e Beauthy Ortho Bond (Shofu) e AdheSE e Helioset Ortodontic (Ivoclar Vivadent), são eficientes para a colagem de braquetes ortodônticos.

Retamoso et al.(2006) observaram o índice de adesivo remanescente (IAR) e constataram que para os adesivos autocondicionantes, as falhas de união ocorreram na interface braquete/ adesivo representando um risco de fratura de esmalte menor quando comparada com os convencionais. Além disso, os autocondicionantes apresentaram valores médios de resistência de união entre 10,9
$\mathrm{MPa}$ e 12,89 $\mathrm{MPa}$, enquanto que para o adesivos convencionais foi de $15,96 \mathrm{MPa}$. A partir desses resultados, concluíram que a resistência adesiva dos autocondicionantes, embora apresente valores menores, do ponto de vista clínico é semelhante aos dos adesivos convencionais.

A resistência de união e de fadiga dos sistemas adesivos convencionais e autocondicionantes foram avaliadas em estudo realizado por Ericson (2006), o qual demonstrou que os sistemas convencionais obtiveram vantagens quando comparados ao autocondicionantes em ambos os testes. Porém, o autor sugeriu que os testes de fadiga devem ser realizados em conjunto com os testes de resistência de união para melhor avaliação do desempenho dos adesivos. Sistemas adesivos com ácido fosfórico também apresentaram melhores resultados na resistência de união de braquetes do que sistemas autocondicionantes, como relatam Farina et al.(2008) e Minick et al.(2009), que também afirmaram que a força do adesivo autocondicionante iBond é inferior ao que seria aceitável para utilidade clínica.

O método de aplicação dos sistemas adesivos autocondicionantes, ativo (esfregaço) ou inativo (sem esfregaço), também é um fator considerável que interfere na efetividade clínica. Amaral et al.(2009) concluíram por meio de um estudo que a utilização da técnica ativa melhora o desempenho da ligação dos sistemas adesivos autocondicionantes com a estrutura dental.

Outro fator estudado foi o tempo de aplicação dos adesivos autocondicionantes em relação aos convencionais. Marquezini (2003) utilizou para autocondicionantes tempos de 20,30 e 45 segundos, para ácido fosfórico $35 \%$ com adesivo convencional por 10 segundos mais 20 segundos do adesivo e apenas para o adesivo convencional por 30 segundos. Com isso, concluiu que a extensão do tempo de condicionamento ácido ou de aplicação não resultou em maior resistência de união dos sistemas autocondicionantes ao esmalte.

\section{Discussão}

Muitos pesquisadores têm investigado materiais que possam ser adotados como alternativa 
ao condicionamento do esmalte dental para colagem de braquetes, com o objetivo de definir qual a técnica e material com maior eficiência para uma prática clínica satisfatória (HOSEIN, 2004; YAMAMOTO, 2007; OLIVEIRA, 2001; GRUBISA, 2004; MINICK, 2009; AMARAL, 2009; MARQUEZINI, 2003).

Os adesivos autocondicionantes correspondem a uma nova geração de materiais ortodônticos que pretendem minimizar os danos causados pelo condicionamento ácido direto (ácido fosfórico) sobre a superfície do esmalte, com a mesma eficácia e possibilidade de redução do tempo clínico (TATIM, 2010; PASCHOS, 2007; HOSEIN, 2004; YAMAMOTO, 2007).

Quanto às propriedades físico-químicas dos adesivos autocondicionantes e modificações suscitadas no esmalte entende-se que os sistemas convencionais adesivos são materiais que ainda exigem um prévio condicionamento ácido. Somente após lavagem e secagem, a sua aplicação à estrutura dental é permitida (BUONOCORE, 1955; MIYAZAKI,1999). Em contrapartida, com o objetivo de eliminar esse passo clínico e possibilitar uma maior segurança em relação à área atingida pelo adesivo, os sistemas autocondicionantes contam com a incorporação de ácido em sua composição (MIYAZAKI,1999; REIS, 2009; MIYAZAKI, 2000; NETTO, 2003). Para estabilizar a ação ácida dos monômeros, a água presente na formulação ${ }^{7} \mathrm{e}$ a capacidade de tamponamento apresentada pela estrutura mineralizada do dente equilibram sua ação desmineralizante.

Alguns pesquisadores (FREY, 2000; CACCIAFESTA, 2003; HOSEIN, 2004) encontraram resultados satisfatórios no que diz respeito à resistência de união apresentados pelos sistemas autocondicionantes. No entanto, de acordo com outros autores (PASCHOS, 2007; DE MUNCK, 2005; VAN LANDUYT, 2007; LOPES, 2004), por sua menor agressividade ao esmalte, eles apresentam resistência e adesão inferiores aos sistemas convencionais, contudo, mostram resultados clinicamente aceitáveis para o seu uso (DE MUNCK, 2005; VAN LANDUYT, 2007).

Estudos (HOSEIN, 2004; YANAMOTO, 2007; RETAMOSO, 2006) demonstraram que as vantagens e desvantagens dos adesivos autocondicionantes em comparação com os sistemas convencionais estão principalmente relacionadas com a quantidade de esmalte perdido, a estrutura da interface esmalte/adesivo e quantidade de adesivo remanescente, visto que técnicas autocondicionantes apresentaram menor perda de esmalte, interface esmalte/adesivo mais regularizada e menor quantidade de adesivo remanescente após descolagem de braquetes, o que indica este último fator, um aumento do risco de fratura coesiva do esmalte.

Quanto ao tempo de aplicação e efetividade clínica, os sistemas adesivos autocondicionantes apresentam divergência de opiniões entre pesquisadores. Enquanto na literatura é ressaltada uma boa resistência de união ${ }^{29}$, surgem controvérsias entre outros autores (GRUBISA, 2004; RETAMOSO, 2006; ERICKSON, 2006; FARINA, 2008; MINICK, 2009) que afirmam menor resistência de união, porém admissível do ponto de vista clínico, ou resistência equivalente aos convencionais.

O tempo de aplicação não interfere na ação adesiva efetivamente (MARQUEZINI JR, 2003), porém o modo como o adesivo autocondicionante é aplicado, ativa ou passivamente, influencia na sua efetividade e estabilidade à longo prazo, havendo necessidade de diferentes metodologias para a avaliação do comportamento dos adesivos autocondicionantes (AMARAL, 2009).

Aparentemente o uso de autocondicionantes em Dentística, é questionado (LOPES, 2004), e por essa razão é sugerido um prévio condicionamento da estrutura dental com ácido fosfórico para garantir uma maior resistência de união. Porém na Ortodontia, onde a colagem de braquetes é provisória/ transitória, o prévio condicionamento não deve ser aplicado, pois uma resistência de união superior a 8 MPa clinicamente fornece uma colagem aceitável que resiste aos esforços mastigatórios e a pressão exercida pelos arcos ortodônticos (FREY, 2000; CACCIAFESTA, 2003; DE MUNCK, 2005; VAN LANDUYT, 2007; HOSEIN, 2004).

Os sistemas adesivos autocondicionantes correspondem a uma inovação da ciência, contudo, toda inovação leva um determinado tempo para ser aprovada e adotada definitivamente. Isso exige um 
maior número de estudos que devem ser realizados nesta área, principalmente em Ortodontia, para comprovar sua eficiência clínica.

\section{Conclusão}

Baseado na revisão de literatura é lícito concluir que os adesivos autocondicionantes:

1. Apresentam em sua composição a incorporação de derivados do ácido carboxílico (4-MET) ou monômeros fosfonados (Fenil-P, 10-MDP e PENTA), a presença de água $\left(\mathrm{H}_{2} \mathrm{O}\right)$, com $\mathrm{pH}$ em torno de 1 e 2 .

2. Proporcionam uma perda menor de quantidade de esmalte; menor risco de fratura de esmalte quando comparados aos convencionais;

3. O tempo de aplicação dos adesivos autocondicionantes deve obedecer às normas do fabricante;

4. A resistência de união dos autocondicionantes ainda é discutida, apresenta grande variabilidade de resultados, principalmente em Ortodontia, sugerindo que mais estudos sejam realizados para que se possa comprovar a eficiência desses adesivos.

\section{REFERÊNCIAS}

AMARAL, R. C.; STANISLAMVCZUK, R.; ZANDERGRANDE, C.; MICHEL, M. D.; REIS, A.; LOGUERCIO, A. D. Active application improves the bonding performance of self-etch adhesive to dentin. Journal of Dentistry, v.37, p.82-90, 2009.

BUONOCORE, M. G. A simple method of increasing the adhesion of acrylic filling materials to enamel surfaces. J Dent Res., v.34, n.6, p.849-53, Dec., 1955.

CACCIAFESTA, V.; SFONDRINI, M. F.; DE ANGELIS, M.; SCRIBANTE, A.; KLERSY, C. Effect of water and saliva contamination on shear bond strength of brackets bonded with conventional, hydrophilic, and self-etching primers. American Journal of Orthodontics and Dentofacial Orthopedics, v.123, n.6, p. 633-640, 2003.
CARVALHO, R. M.; CARRILHO, M. R. O.; PEREIRA, L. C. G.; GARCIA, F. C. P.; MARQUEZINI JR, L.; SILVA, S. M. A. et al. Sistemas adesivos: fundamentos para a compreensão de sua aplicação e desempenho em clinica. Biodonto, v.2, n.1, p.8-86, 2004.

DE MUNCK, J., VAN LANDUYT, K., PEUMANS, M., POITEVIN, A., LAMBRECHTS, P., BRAEM, M. et al. A critical review of the durability of adhesion to tooth tissue: methods and results. J Dent Res., v.84, n.2, p.118-32, 2005.

ELIADES, T.; BRANTLEY, W. A. The inappropriateness of conventional orthodontic bond strength assessments protocols. The European Journal of Orthodontics, v.22, n.1, p. 1323,2000 .

ERICKSON, R. L.; GEE, A. J DE, FEILZER, A. J. Fatigue testing of enamel bonds with self-etch adhesive systems. Dental Materials, v. 22, p. 981-987, 2006.

FARINA, A. P.; CECCHIN, D.; WOITCHUMAS, D. R. Resistência de união de brackets ortodônticos ao esmalte dental usando diferentes sistemas adesivos. RFO, v. 13, n. 1, p. 55-59, jan/abril 2008.

FLORIANO, H.; MORI A. T.; MALTAGLIATI A. M. A.; LINO A. P. Estudos da resistência à tração de braquetes metálicos colados em relação a alguns tipos de base. Rev. Paul Odontol.; v.23, n.2, p.20-3, 2001.

FREY, O. Creating a reliable bond. An all-in-one system. Am J Dent., v.13(Spec), p.85, 2000.

GARONE FILHO, W. Adesão em esmalte e dentina. In: CARDOSO, R. J. A.; GOLÇALVES, E. A. N. Dentistica / laser. São Paulo: Artes Medicas; 2002. p. 27-55.

GRUBISA, H. S. I.; HEO, G.; RABOUD, D. An evaluation and comparison of orthodontic bracket bond strengths achieved with self-etching primer. Am. J. Orthod. Dentofacial Orthop., v.126, p.213-219, 2004.

HOSEIN, I.; SHERRIFF, M.; IRELAND, A. J. Enamel loss during bonding, debonding, and cleanup with use of a selfetching primer. Am. J. Orthod. Dentofacial Orthop., v.126, p.717-724, 2004.

LOPES, G. C.; MARSON, F. C.; VIEIRA, L. C.; CALDEIRA, A. M.; BARATIERI, L. N. Composite bond strength to enamel with self-etching primers. Oper Dent.; v.29, n.4, p.424-9, 2004.

MARQUEZINI JR. L. Efeito do tempo de aplicação de adesivos autocondicionantes na durabilidade da união ao esmalte. [Dissertação de Mestrado]. Bauru: Faculdade de Odontologia de Bauru USP, 2003.

MINICK, G. T.; OESTERLE, L. J.; NEWNAM, S. M.; SHELLHART, W. C. Bracket bond strengths of new adhesive systems. American Journal of Orthodontics and Dentofacial Orthopedics, v.135, p. 771-776, June 2009. 
MILLET, D. T.; MCCABE, J. B. Orthodontic Bonding with glass ionomer cement - a review. The European Journal of Orthodontics., v.18, n.4, p.385-399, 1996.

MIYAZAKI, M. et al. Influence of self-etching primer drying time on enamel bond strength of resin composites. J. Dent., v.27, n.3, p.203-7, Mar. 1999.

MIYAZAKI, M.; SATO, M.; ONOSE, H. Durability of enamel bond strength of simplified bonding systems. Oper Dent., v. 25, n.2, p.75-80, 2000.

NETTO, G.; NARCISO, L. et al. Introdução à dentistica restauradora: diagnóstico, prevenção, proteção da polpa, hipersensibilidade dentinária, adesão. São Paulo: Santos Livraria, 2003. 283 pág.

OLIVEIRA, W. J.; PAGANI, C.; RODRIGUES, J. R. Comparison of the shear bond strenght between two self etching adhesive systems in bovine enamel. Pós-Grad. Rev. Fac. Odontol. São José dos Campos. v.4, n.2, mai/ago. 2001.

PASCHOS, E.; WESTPHAL, J. O.; ILIE, N.; HUTH, K. C.; HICKEL, R.; JANSON, I. R. Artificial saliva contamination effects on bond strength of self-etching primers. The Angle Orthodontist., v.78, n.4, p.716-721, 2007.

PERDIGÃO, J.; GERALDELI, S. Bonding characteristics of self-etching adhesives to intact versus prepared enamel. J Esthet Rest Dent.; v.15, n.32, p.32-42, 2003.

PERDIGÃO, J.; GOMES, G.; LOPES, M. M. Influence of conditioning time on enamel adhesion. Quintessence International, v.37, n.1, p. 35-41, 2006.

REIS, A.; LOGUERCIO, A. D. Materiais dentários diretos: dos fundamentos à aplicação clinica. São Paulo: Santos, 2009, p. 423 .

REIS, A.; SANTOS, J. E.; LOGUERCIO, A.; BAUER JR, O. Eighteen- month bracket survival rate: conventional versus self-etch adhesive. The European Journal of Orthodontics., v.30, n.1, p. 94-99, 2008.

RETAMOSO, L. B., COLLARES, F. M., SAMUEL, S. M. W., FERREIRA, E. S. Influência do sistema adesivo na resistência de união de "brackets": um estudo "in vitro". R. Fac. Odontol. Porto Alegre. v.47, n.3, p.14-16, dez 2006.

RETIEF, D. H. Failure at the dental adhesive etched enamel interface. Journal of Oral Rehabilitation. v.1, n.3, p.265274, 1974.

REYNOLDS, I. R. A review of direct orthodontics bonding. British Journal of Orthodontics. v. 2, n.2, p.171-178, 1975.

ROMANO, F. L.; CORRER, S. L.; NOUER, D. F.; CORRER, A. B.; SINHORETI, M. A. C.; MAGNANI, M. B. B. A. Shear bond strength of metallic brackets bonded with four different composite resins. Brazilian Journal of Oral Sciences, Piracicaba, v.6, n.23, p.1457-1461, 2007.
RYOU, D. B.; PARK, H. S.; KIM, K. H.; KWON, T. Y. Use of Flowable Composites for Orthodontic Bracket Bonding. The Angle Orthodontist, v.78, n.6, p.1105-1109, 2008.

SCOUGALL-VILCHIS, R. J.; YAMAMOTO, S.; KITAI, N.; YAMAMOTO, K. Shear bond strength of Orthodontic brackets bonded with different self-etching adhesives. American Journal of Orthodontics and Dentofacial Orthopedics., v. 136, p.425-430, sept 2009.

TATIM, L. M.; COELHO, U.; JIMENEZ, E. E. O.; DIVARDIM, S. Influencia da velocidade de carga nos testes de cisalhamento em colagem de braquetes. Rev Ortho Science, v.3, n.9, p.9-15, jan/mar 2010.

TORTAMANO, A.; VIGORITO, J. W.; NAUFF, F.; GARONE, G. M.; SANTOS, R. S. C. Avaliação da resistência à tração de agentes cimentantes para braquetes ortodônticos. Rev Assoc Paul Cir Dent., v.56, n.4, p.259-63, 2002.

VAN LANDUYT, K. L.; SNAUWAERT, J.; DE MUNCK, J.; PEUMANS, M.; YOSHIDA, Y.; POITEVIN, A. et al. Systematic review of the chemical composition of contemporary dental adhesives. Biomaterials, v.28, p.375785, 2007.

VALLETA, R.; PRISCO, D.; DE SANTIS, R.; AMBROSIO, L.; MARTINA, R. Evaluation of the debonding strength of orthodontic brackets using three different bonding systems. The European Journal of Orthodontics, v. 29, n.6, p. 571577, 2007.

YANAMOTO, K.; VILCHIS, R. J. S.; HOTTA, Y. Examination of enamel-adhesive interface with focused íon beam and scanning electron microscopy. American Journal of Orthodontics an Dentofacial Orthopedes, v. 131, n.5, p. 646-650, 2007. 